\title{
Perceptions of professionalism in dentistry - a qualitative study
}

IN BRIEF

- Highlights that professionalism is an essential competence for dental professionals, but to date there is no agreed definition of this construct.

- Explores professionalism in dentistry using theory and empirical data, and produces not only a definition but also a model that can form the basis of an assessment system.

Objectives Professionalism is an essential competence for dental professionals. Dental educators require both a clear definition and an understanding of the scope of professionalism in order to teach and assess it. The aim of this study was to identify concepts of professionalism in dentistry and the themes within this construct. Method Semi-structured interviews with participants purposively sampled to ensure representation of relevant viewpoints. Qualitative framework analysis was used to induct themes. Results Four themes arose from the data: (i) professionalism as a second order competence, (ii) the expression of professionalism as dependent on context, (iii) reflection as a necessary component and (iv) professionalism encompasses both tacit and overt personal aspects. These results were then incorporated into a conceptual model of dental professionalism. Conclusions Analysis of the interview data reveals that participants conceptualise professionalism as the manner in which one reflects on and reconciles different aspects of professional practice, which demonstrates acceptance of professional responsibility and accountability. It is manifested in the manner in which work is carried out. The definition and model conceptualise the construct of professionalism within dentistry that can be used to derive an educational and assessment system.

\section{INTRODUCTION}

Professionalism is a broad competency needed by dentists to act effectively, acceptably and ethically and is seen as a central part of both undergraduate and postgraduate curricula. ${ }^{1-4}$

Traditionally, professionalism has been concerned with the norms, values and behaviour of dentists as they carry out their daily work. ${ }^{1,3,5}$ Within the dental literature it has been described as an important aspect of competence. ${ }^{3,4}$ While most descriptions include ethics and jurisprudence along with appropriate behaviour towards patients and members of the dental team, other aspects range in prominence. These variable aspects

\footnotetext{
'Academic Unit of Restorative Dentistry, School of Clinical Dentistry, University of Sheffield, Claremont Crescent, Sheffield, S10 2TA; ${ }^{2}$ Leeds Institute of Medical Education, University of Leeds, Leeds, LS2 9JT; ${ }^{3}$ Academic Unit of Dental Public Health, School of Clinical Dentistry, University of Sheffield, Claremont Crescent, Sheffield, S10 2TA

${ }^{*}$ Correspondence to: Sandra Zijlstra-Shaw

Email:s.zijlstra-shaw@sheffield.ac.uk; Tel: 01142171932
}

\section{Refereed Paper}

Accepted 26 July 2013

DOI: $10.1038 /$ sj.bdj.2013.1048

${ }^{\circledR}$ British Dental Journal 2013; 215: E18 include knowledge of the social and psychological issues relevant to the care of patients, ability to maintain a safe working environment, awareness of the impact of the dentist's own health on the ability to practice dentistry, and the need for continued professional development.

This breadth and diversity is reflected in reviews that demonstrate that professionalism is variable, includes both normative and ideological aspects, and is based both on the context and the individual. ${ }^{6-10}$ The ideological aspects such as altruism, honour and integrity have been described by Inui ${ }^{11}$ as being the qualities expected of a 'virtuous citizen', while the normative nature of professionalism is frequently seen in advice from professional bodies, such as Standards for dental professionals ${ }^{5}$ or Duties of a doctor. ${ }^{12}$ Trust and discretion, autonomy, responsibility and accountability play vital roles in the characterisation of professionalism and these factors are used for both public benefit and that of the individual client. ${ }^{11,13,14}$

The UK General Dental Council (GDC) ${ }^{2}$ requires assessment of professionalism throughout the undergraduate programme and continues to include professionalism in its learning outcomes. ${ }^{15}$ Assessment methods for evaluating knowledge and skills have been described ${ }^{16,17}$ and there is an extensive literature on the assessment of professionalism within medical education. ${ }^{6,18-20}$ Moreover, educators must produce clear expectations for which students can strive. ${ }^{21}$ Thus, dental educators should understand precisely what is meant by 'professionalism' in relation to dentistry in order to both teach and assess it.

Despite this need for assessment of professionalism within both dentistry and medicine, no single instrument has been found to measure it. ${ }^{22}$ The main reasons for this relate to a lack of a concrete definition and an operationalisation of this complex construct. Moreover, while there appear to be many parallels in the literature between medical and dental professionalism, to the point that definitions in the dental literature use medical sources, ${ }^{23,24}$ no empirical evidence can be found that demonstrate this relationship. Indeed a recent literature review concludes that without a validated definition, assessment of professionalism within dental education will be compromised. ${ }^{10}$ Thus, the 
rationale for this study was to provide a definition and to understand the scope of professionalism within dentistry.

The aim of this study was to describe concepts of professionalism in relation to dentistry, and the themes and aspects within it. The intention was that this would lead to a definition of professionalism in dentistry and the development of a construct upon which assessments could be based.

\section{METHOD}

Qualitative methods were used as they consist of 'a set of interpretive material practices that makes the world visible'. ${ }^{25}$ Qualitative methods provide descriptive information, aid conceptualisation and emphasise understanding of phenomena. ${ }^{26}$ Semi-structured, open-ended interviews with participants selected by purposive sampling were carried out. The data were then analysed using framework analysis. ${ }^{27}$

Participants were selected to provide a broad range of experiences and views and were identified using a matrix drawn up to mirror the Royal College of Physicians working party on professionalism in medicine. ${ }^{14}$ This ensured that participants represented a range of ages and genders and the perspectives of patients, as well as dentists and other dental professionals. Participants were contacted following the acquisition of ethical approval from the University of Sheffield research ethics process.

Participants were initially contacted by email to inform them of the study and inviting them to take part. Consent was obtained at the time of interview. Interviews were conducted at a time and place of convenience to the participant, lasted from 40-90 minutes and were semistructured, based around an interview guide. All interviews were audio recorded and transcribed verbatim by one researcher (SZS) and carried out between January 2010 and February 2011.

Data were analysed using 'framework analysis' ${ }^{27-28}$ in five stages. First, the primary researcher re-read the transcripts and listed key ideas and recurrent themes to ensure familiarisation. Secondly, a detailed index of the data was produced to enable subsequent retrieval and exploration. Thirdly, the data were arranged within the framework using abstraction and synthesis to produce distilled summaries of the views expressed. The initial framework was derived from the literature and included seven major themes: definitions of professionalism, emotional intelligence, professional image, changes over time, learn by experience, needs a context and affected by culture. However, this needed repeated modification, as themes were elicited from the data. Following each modification a record of all the modifications was made and the previously analysed transcripts were revisited to ensure consistency. Finally, the framework and its emerging themes were used to define concepts, themes and attributes, often personal aspects, within the construct of professionalism within dentistry. The analysis was carried out as a continuous process incorporating new data as it became available, thus enabling modifications in the data collection as themes emerged and ensured that no themes were missed.

Two pilot interviews assessed the interview guide and were included in the full study. In order to ensure the validity of the framework the primary researcher (SZS) discussed each stage of the analysis with the research team. Once saturation was reached, that is no further themes were elicited, data collection was halted. Fifteen interviews were conducted. No new themes emerged after interview 12.

Of the eventual 15 participants, 9 were male and their age groups ranged from 20-25 years to 60-65 years. Participants, included both lay (one) and dentally qualified (one) members of the GDC, experienced (four) and newly qualified general dental practitioners (two), dentally qualified consultants in a number of differing specialities (four), registered dental care professionals (two) and students (two). Nine were dentally qualified of whom seven had considerable experience in general dental practice. There were two patient representatives. Eleven participants were involved in dental education at either undergraduate or postgraduate level. These numbers total more than 15 because several participants fell into more than one category.

\section{RESULTS}

Analysis of the interview data reveals that participants conceptualise professionalism as the manner in which one reflects on and reconciles different aspects of professional practice, which demonstrates acceptance of professional responsibility and accountability. It is manifested in the manner in which work is carried out. The balance of the various aspects varies with and is appropriate to the context. Accountability means that the professional is expected to be able to justify his/her actions to the patient, the profession, the society in which they work and themselves.

Four key themes emerged from the data. These were:

- Professionalism as a second order competence

- The expression of professionalism as dependent on context

- Reflection as a necessary component

- Professionalism encompassing personal aspects that are both tacit and overt.

The themes are illustrated with anonymised quotations from the data.

Professionalism appears as a second order competence; that is, a competence which is demonstrated only when carrying out another, first order competence. It encompasses and is demonstrated while carrying out first order competences such as technical skills, communication and interpersonal skills, and leadership and management skills. This distinction is described in both the literature ${ }^{6,29}$ and the data where it was seen as vague and related to the way of thinking. The second order nature arose because;

'People might argue that professionalism is actually more about a way of thinking' (4-P-2b).

Thus, while professionalism might encompass technical and communication skills, these were manifestations of something that was vague;

'Professionalism is more than just carrying out the role of being the dentist in the dental surgery' (7-P-27).

Furthermore, professionalism encompassed both attitudes and behaviours;

'It goes beyond the behaviour that you can see' (11-P-8a).

Context dependence recognised that 'professionalism' varied in relation to many external factors. It was expressed within the data in a number of ways including flexibility, changes over time, 
variations in professional image and the influence of both culture and institution. For example professionalism changing over time was expressed as follows;

'We are talking about something that is relevant now and to, you know, the current generations, rather than just accepting the dogma of what professionalism was in the past' (4-P-25c).

The influence of institution and culture included descriptions of the work setting and how this affected professionalism;

'You also, I think, are very often guided by the people with whom you work and the settings you go into' (5-P-34).

The overarching theme of professionalism was the process of reflecting on applying and reconciling; a process described as harmonising all the different aspects of professionalism to situations in everyday living, within, but also beyond clinical practice. This reflection could then manifest in behaviours in those situations.

The personal aspects could be tacit or overt. Here the term 'tacit' is used in a similar manner to 'tacit knowledge' as described by Polanyi, ${ }^{30}$ that is they are aspects which are used without conscious awareness. Overt aspects were the first order behaviours that were more directly interpretable.

These themes and aspects can be arranged graphically in a framework (Fig. 1).The remainder of the results will be described using this framework.

Tacit aspects included 'awareness', which comprised of self-awareness;

'Always being aware that people have limitations and things and what your own limitations are' (5-P-7a).

As well as awareness of the needs of others (patient, other members of the dental teams, etc). This was related to feelings;

'I suppose your emotional intelligence comes into it... be aware of them, try and pick up on non-verbal clues' (8-P-7b).

Trust was a particularly important theme and included both overt aspects, such as honesty, integrity and fairness, alongside tacit aspects relating to the individual's ability to instil trust and actually be trustworthy. Descriptions included;

'I think that idea of honesty, a general duty of honesty is always there' (4-P-3b).

'You'd be fair, I think there's got to be an element of fairness' (11-P-8a).

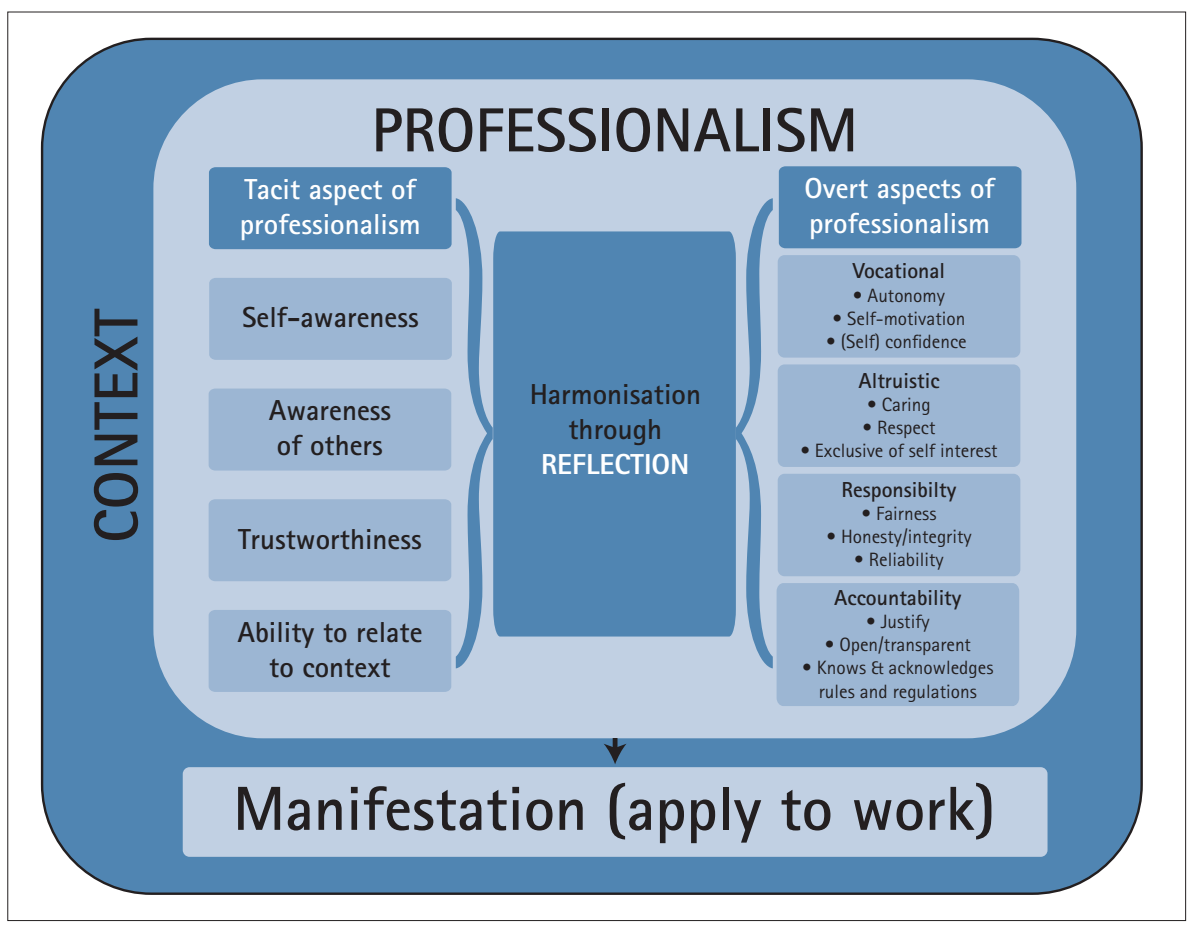

Fig. 1 Model of professionalism in dentistry

Trust was invested within the professional as a personal quality;

'Trust is vital and so therefore to gain trust, the trust is not just in the treatment; the trust is in you as a person' (5-P-25).

This may explain the link to integrity. Trustworthiness was seen as an awareness of how the professional's actions affected the perception of trust, and thus treatment outcomes;

'If you can instil confidence and trust within them well then, your kind of dentist patient relationship is going to help you throughout the course of treatment and ultimately, I think, result in more successful treatment for the patient' (8-P-6c).

The ability to relate to context was a key theme and a necessary element for professionalism. This was described as the need for flexibility and adaptability;

'You should have the ability to adapt into whatever situation that you are in' (10-P-28b).

Overt aspects related to autonomy, (self-) motivation and (self-)confidence, or more simply, a sense of commitment. This was in turn related to the ability to demonstrate (self-) reflection and reflective learning and may arise out of the individual's selfawareness, alongside the motivation to do something about these;

'If you wanted another aspect of professionalism it is probably to recognise where your shortcomings actually are and to act on them' (7-P-32).

Altruism was seen in such qualities as caring, service to others, respect and the essential need to treat the patient as a person and not just a case, for example;

'I think that is an aspect of professionalism as well, you know, being able to envisage what it's like being sat at the other side of the desk' (6-P-35).

'You just feel that you're not just someone who has come in for dental treatment you are someone who's coming to the dentist who actually knows them and understands what is going on.' (14-P-37).

Altruism was also described as the exclusion of self-interest;

'But you think, right this person's in pain, you know, I think I'll sort this out at my inconvenience, but because I want to kind of sort them out, and that's something that might be a part of professionalism' (10-P-9b).

This consideration of other individuals involved not only patients, but also other members of the dental team and wider considerations relating to society at large. Moreover this had its roots in a form of empathetic reflection;

'I'd like to see more empathy. As I said do as you would be done by, putting yourself in somebody else's position I think is very important' (5-P-20).

The professional's sense of responsibility played an important role and was 
associated with honesty and integrity, fairness and reliability for example;

'I think professionalism is first of all being responsible for what you are doing' (10-P-6a).

'When probity is an issue the dentist is not acting professionally' (7-P-27).

'Patients expect you to be reliable, they expect when they turn up at your surgery they expect you to be there' (5-P-26).

Professional accountability was the ability to justify decisions and actions in an open, transparent way to the patient, professional colleagues, society and themselves in relation to the context. This was expressed both directly as being able to provide justification;

'You should always contact the individuals concerned and explain the reason why you have done this. They may not agree with what you've said, but at least you've been upfront' (9-P-4).

And expressed indirectly as a requirement to be open and transparent when dealing with others;

'Some dentists are fantastic about telling you upfront and making it very clear and that may come from professionalism' (4-P-12).

Reflection was seen as a core component. It was described as 'a way of thinking';

'I think professionalism to me is something more experiential, reflective, thought-based' (4-P-10).

In this way reflection was an overarching theme;

'Not only reflecting on clinical aspects, but reflecting on interactions and relationships and situations, could they have been handled better and if they could, how' (8-P-14b).

This reflective process incorporated;

'An ability to be open to things, to consider other things and yes to make your mind up afterwards' (2-P-32).

The individual professional, once aware of the requirements of the situation, then took each of the themes and personal aspects into consideration

'The more thoughtful a profession the better it would be and therefore it would be reassuring to know that they had thought about all the issues, whatever course of action they decided on' (4-P-13b).

While each of the themes and personal aspects described within the model were necessary they were likely to have differing

Table 1 Triangulation of themes found data and in the literature on professionalism

\begin{tabular}{|c|c|c|}
\hline \multicolumn{2}{|l|}{ Theme } & Reference \\
\hline \multicolumn{2}{|c|}{$\begin{array}{l}\text { Ability to relate to context/context dependent, } \\
\text { including references to internal and external factors }\end{array}$} & $8,32,33,34,35,37,38$ \\
\hline \multicolumn{2}{|c|}{ Second order competence } & 6,29 \\
\hline \multirow{7}{*}{ Personal qualities } & Vocational & $5,6,14,19,32$ \\
\hline & Altruistic & $5,6,14,19,32$ \\
\hline & Self-awareness & $6,8,9,19,32,36$ \\
\hline & Awareness of others & $6,8,9,19,32,36$ \\
\hline & Trustworthiness & $5,6,14,19$ \\
\hline & Responsibility & $5,6,14,19$ \\
\hline & Accountability & $5,6,14,19,36$ \\
\hline \multicolumn{2}{|l|}{ Reflection } & $39,40,41,42,43,44,45$ \\
\hline
\end{tabular}

degrees of importance, depending on the context. The reflective process resulted in a reconciling or harmonisation of the themes and personal aspects, which acknowledged the differing degrees of relevance to the situation

'One has to be able to balance all sorts of things all at once to process all sorts of information' (7-P-50).

This process led to the manifestation of professionalism, which was applied to the other domains of competence, for example, communication skills or technical ability, in the performance of professional work.

\section{DISCUSSION}

This study elicited concepts of professionalism in relation to dentistry. Semi-structured qualitative interviews with participants, purposively sampled to ensure representation of all relevant viewpoints, produced empirical data that was analysed using a thematic framework. This produced both a definition of professionalism and a model of the construct (Fig. 1).

This study is one of the first to explore professionalism in dentistry using theory and empirical data. Moreover, the construct has been operationalised in the form of a model that can be validated and can form a framework for an assessment system within dental education. The study is directly related to dentistry. It is comprehensive and covers all the areas found within the literature on professionalism, for example the ability to relate to context is essential given that professionalism is context dependant.

Professionalism encompasses individual characteristics or personal qualities found in both the data and the literature where reviews by Arnold, ${ }^{6}$ the Royal College of Surgeons ${ }^{14}$ and Stern ${ }^{19}$ described these aspects. However, these aspects were often not described in clear terms, but more as broad desirable qualities, which concurred with the findings of Jha et al. ${ }^{8}$ In this study care was taken to ensure that themes and aspects were carefully defined to ensure that the resulting framework (Fig. 1) could be used to operationalise the construct.

Initial findings were in accordance with the descriptions of professionalism found in the literature (Table 1). Professionalism is socially constructed, ${ }^{7}$ and the data were consistent with the construct being both multifactorial and context dependant. Furthermore, professionalism was seen as a complex construct which, in addition to it being multifactorial, vague and variable, encompasses both attitudes and behaviour.

The importance of the context is seen in the descriptions of the interface between professionalism and aspects of 'fitness to practice'; that is, rules and regulations, and ethics, where the resulting relationship between the three is described, in both the data and by Shaw, ${ }^{31}$ as neither simple nor clear cut. This can be explained by seeing the 'fitness to practice' aspects as part of the external context in which professionalism is manifested. Moreover, all 19 of Monrouxe and colleagues ${ }^{32}$ dimensions of medical professionalism can be seen in the data. Their aspects are expressed as a specific dimension when the appropriate context is encountered. Once again this echoes the context dependant nature of professionalism found in both 
the literature ${ }^{33-35}$ and in the data. This has implications for dental educators as firstly the curriculum needs to provide the students with different contexts in which to experience professionalism and secondly the assessment system must take varying contexts into account.

Personal qualities or aspects were also described that are both tacit and overt. Trustworthiness, self-awareness, awareness of others and the ability to relate to context are seen as being tacit in a similar manner to 'tacit knowledge' as described by Polanyi ${ }^{30}$ who suggested that we know more than we can say. In other words, these aspects are used without conscious awareness, which makes them more difficult to transfer to another person by means of words or symbols and thus they usually require extensive personal contact along with joint or shared activities to be imparted from one person to another. This has important consequences for dental educators as this must be taken into consideration when designing curricula.

The overt aspects of professionalism include personal qualities such as altruism and a sense of vocation alongside responsibility and accountability. These are more easily explained in verbal terms and result in more readily interpretable behaviours. Accountability and responsibility involve not only the patient, but also professional colleagues, society and themselves. This can been seen in van de Camp and colleagues'36 framework for assessing general medical practitioners, in which they describe professional behaviour towards the patient, other professionals, the public and oneself.

Both the personal aspects and the context dependence evident in the data concur with those seen in the descriptions of the internal and external factors described in the literature on medical professionalism. For example, all of Hilton and Slotnik's ${ }^{37}$ themes are found in the data, as is reference to those described by Stern. ${ }^{19}$ Describing the features elicited as internal and external not only concurs with Hilton and Slotnik, ${ }^{37}$ but also echoes Hafferty and Castellani. ${ }^{38}$ The latter suggest that professionalism from a medical point of view is centred around individual's characteristics, but that from a sociological point of view the contribution of the method of organisation of work plays a central theme. It would therefore be reasonable to assume that both internal and external factors play a role. However, the internal factors relate to all the personal aspects while the external factors relate to the context and this may give rise to confusion between the tacit and overt nature of the personal aspects. This has profound significance for dental educators as they not only have to explain what is required of dental students, but they also have to provide appropriate experiences for the students in order to allow them to acquire and develop all the personal aspects in many different contexts. This in turn will then need to be taken into consideration when designing any assessment system.

Finally, the importance of reflection as a component of professionalism was both a central theme of the data and within the literature..$^{39-43}$ Many descriptions of reflection begin with 'awareness', 39,40,44 as do descriptions of ethical decision making, ${ }^{45}$ which was found within the data. The second stage of reflection is described by Murphy and Atkins ${ }^{44}$ as a 'critical analysis of feelings and knowledge'. This occurred in the data where professionalism encompassed both feelings and knowledge. The third stage in Murphy and Atkins' description ${ }^{44}$ is the development of a new perspective on the situation, which echoes Rest's ${ }^{45}$ 'make a moral judgement' and 'exercise moral intent'. Our data revealed the ability to reflect and make decisions based on many different factors is context dependent. It is when the individual acts on the 'moral intent' that there is a relationship between moral decision making and behaviours. Thus, the manifestation of professionalism is the manner in which work is carried out.

Furthermore, combining the fact that professionalism needs a context in which to be exercised with the presence of the individual's personal qualities results in the necessity to harmonise the internal aspects with the external contextual factors. Therefore, reflection is an essential element of professionalism.

This triangulation against existing ideas validates our findings. However, this study adds to understanding by clarifying the diverse ideas and bringing them together in a comprehensive, specified and structural model. Unlike earlier research these findings relate directly to dental professionalism (rather than medicine) and meet a need in that profession. Importantly, they are rooted in theory but also empirically driven.

Certain aspects of the methods of the study warrant consideration. The intention in qualitative studies is not to generate statistically representative views but to capture the breadth and depth of perspectives. This is achieved by purposively sampling a wide range of participants and by reaching saturation in the data where no new themes emerge. It is validated by triangulating the data analysis between researchers and by comparing findings with existing knowledge. The lack of further factors elicited from the most recent interviews coupled with the resonance with all the areas of professionalism described in the literature confirms that saturation was achieved and that there is a major overlap between professionalism in dentistry and medicine.

Our findings derive from interviews carried out within the UK, where the dental profession is regulated by a single independent body. Therefore, it is possible that they may not be generalisable to settings within different regulatory and business contexts. Nevertheless, the data are compatible with those published about dental and medical professionalism, which suggests that the themes and their interrelationships are generalisable across wider contexts. As noted earlier, this study was empirical and drew its data from a wide variety of stakeholders, which also enhances its conceptual generalisability. The principal researcher has a long interest in professionalism, was familiar with the literature and was readily able to draw up an initial framework to aid the analysis. However, the revisions of the framework during the study are evidence of considerable response to the data.

\section{CONCLUSION}

Professionalism is a second order competence. It can be defined as the manner in which one reflects on and reconciles different aspects of professional practice, which demonstrates acceptance of professional responsibility and accountability. It is manifested in the manner in which work is carried out. The balance of the various aspects will vary with 
and be appropriate to the context while accountability means that the professional is expected to be able to justify his/her actions to the patient, the profession, the society in which they work and themselves. The definition and model conceptualise the construct of professionalism within dentistry, which can be further validated and used to derive an educational and assessment system for it.

1. Brown G, Manogue M, Rohlin M. Assessing attitudes in dental education: is it worthwhile? Br Dent J 2002: 193: 703-707.

2. General Dental Council. The first five years, third edition (interim). London: GDC, 2008. Online edition available at http://www.gdc-uk org/ Newsandpublications/Publications/Publications/ TFFYthirdeditionfinal1[1].pdf (accessed August 2013).

3. Cowpe J, Plasschaert A, Harzer W, Vinkka-Puhakka $\mathrm{H}$, Walmsley A D. Profile and competences for the European dentist - update 2009. Association for Dental Education in Europe, 2009. Online article available at $h$ ttp://www.adee.org/documents/ taskforces/tfi_profile_competence_2010.pdf (accessed August 2013).

4. Committee of Postgraduate Dental Deans and Directors. A curriculum for UK Dental Foundation Programme Training. London: COPDEND, 2006.

5. General Dental Council. Standards for dental professionals. London: GDC, 2005.

6. Arnold L. Assessing professional behaviour: yesterday, today, and tomorrow. Acad Med 2002 77: 502-515

7. Evetts J. The sociological analysis of professionalism: occupational change in the modern world. Int Socio/ 2003; 18: 395-415.

8. Jha, V, Bekker, H L, Duffy, S R G, Roberts T E. Perceptions of professionalism in medicine: a qualitative study. Med Ed 2006; 40: 1027-1036.

9. Van de Camp K, Vernooij-Dassen M, Grol R, Bottema B. How to conceptualise professionalism: a qualitative study. Med Teacher 2004; 6: 696-702.

10. Zijlstra-Shaw S, Robinson P G, Roberts T E. Assessing professionalism within dental education: the need for a definition. Eur J Dent Educ 2011 15: $1-9$

11. Inui T S. Flag in the wind: educating for professionalism in medicine Washington DC: Association of American Medical Colleges, 2003.
12. General Medical Council. Duties of a doctor. London: The General Medical Council 2006.

13. Royal College of Physicians and Surgeons of Canada The CanMEDS physician competency framework. Ottawa: The Royal College of Physicians and Surgeons of Canada, 2006.

14. Royal College of Physicians of London. Doctors in society: medical professionalism in a changing world. Report of a Working Party of the Royal College of Physicians of London. London: Roya College of Physicians of London, 2005.

15. General Dental Council. Preparing for practice: dental team learning outcomes for registration. London: GDC, 2011.

16. Brown G, Bull J, Pendlebury M. Assessing studen learning in higher education. London: Routledge 1997.

17. Norman G. Van der Vleuten, C, Newble D (eds). International handbook of research in medical education. Dordrecht: Kluwer Academic Publishers, 2002

18. Lynch D C, Surdyk, P M, Eiser A R. Assessing professionalism: a review of the literature. Med Teacher 2004; 26: 366-373.

19. Stern D T (ed). Measuring medical professionalism Oxford: Oxford University Press, 2006

20. Veloski J J, Fields S K, James R N, Boex R, Blank L L Measuring professionalism: a review of studies with instruments reported in the literature between 1982 and 2002. Acad Med 2005; 80: 366-370.

21. Stern D T, Papadakis M. The developing physician - becoming a professional. The New Eng J of Med 2006; 355: 1794-1799.

22. Jha V, Bekker H L, Duffy SR G, Roberts T E. A systematic review of studies assessing and facilitating attitudes towards professionalism in medicine. Med Ed 2007; 41: 822-829.

23. Nath C, Schmidt R, Gunel E. Perceptions of professionalism vary most with educational rank and age. J of Dent Ed 2006; 70: 825-834.

24. Trathen A, Gallagher J E. Dental professionalism: definitions and debate. Br Dent J 2009. 206: 249-253.

25. Denzin N K, Lincoln Y S. Handbook of qualitative research. London: Sage, 2000.

26. Murphy E, Dingwall $R$, Greatbatch D, Parker $S$ Watson P. Qualitative research methods in health technology assessment: a review of the literature. Health Technol Assess 1998: 2

27. Ritchie J, Lewis J. Qualitative research practice. London: Sage Publications, 2003

28. Pope C, Ziebland S, Mays N. Qualitative research in health care: analysing qualitative data. Br Med $\rfloor$ 2000; 320: 114-116.
29. Verkerk M A, De Bree M J, Mourits M J. Reflective professionalism: interpreting CanMEDS 'professionalism'. J Med Ethics 2007; 33: 663-666.

30. Polanyi M. The tacit dimension. New York: Anchor Books, 1967. Reprinted University of Chicago press, 2009.

31. Shaw D. Ethics, professionalism and fitness to practise: three concepts, not one. Br Dent J 2009; 207: 59-62.

32. Monrouxe LV, Rees C E, Hu W. Differences in medical students' explicit discourses of professionalism: acting, representing, becoming. Med Ed 2011; 45: 585-602.

33. Ginsburg S, Regehr G, Hatala R et al. Context, conflict, and resolution: a New conceptual framework for evaluating professionalism. Acad Med 2000; 75: S74-S78.

34. Ginsburg S, Regehr G, Lingard L. Basing the evaluation of professionalism on observable behaviours: a cautionary tale. Acad Med 2004; 79: $\mathrm{S1-4}$

35. Ginsburg S, Regehr G, Mylopoulos M. From behaviours to attributions: further concerns regarding the evaluation of professionalism. Med Ed 2009: 43: 414-425.

36. Van de Camp K, Vernooij-Dassen M, Grol R, Bottema B. Professionalism in general practice: development of an instrument to assess professional behaviour in general practitioner trainees. Med Ed 2006; 40: 43-50.

37. Hilton, S R, Slotnick H B. Proto-professionalism: how professionalisation occurs across the continuum of medical education. Med Ed 2005; 39: 58-65.

38. Hafferty F W, Castellani B A. Sociological framing of medicine's modern-day professionalism movement Med Ed 2009; 43: 826-828.

39. Schon D. The reflective practitioner: how professionals think in action. New York: Basic Books, 1983

40. Boud D, Keogh R, Walker D. Reflection turning experience into learning. London: Kegan Page, 1985

41. Eraut M. Developing professional knowledge and competence. London: Falmer, 1994.

42. Boenink A D. Teaching and learning reflection on medical professionalism. Unpublished PhD. Free University of Amsterdam, 2006.

43. Aukes $L$ Personal reflection in medical education. Unpublished PhD. University of Groningen, 2008.

44. Atkins S, Murphy K. Reflection: a review of the literature. J Adv Nurs 1993; 18: 1188-1192.

45. Rest J R. Research on moral development: implications for training counseling psychologists. The Counselling Psychologist 1984; 12: 19-29. 